\title{
Direct battery-driven solar LED lighting using constant-power control
}

\author{
Bin-Juine Huang*, Chun-Wei Chen, Po-Chien Hsu, Wei-Min Tseng, Min-Sheng Wu \\ New Energy Center, Department of Mechanical Engineering, National Taiwan University, Taipei 106, Taiwan \\ Received 21 February 2012; received in revised form 16 July 2012; accepted 23 July 2012
}

Communicated by: Associate Editor Nicola Romeo

\begin{abstract}
A direct battery-driven LED lighting technique using constant-power control is proposed in the present study. A system dynamics model of LED luminaire was derived and used in the design of the feedback constant-power control system. The test result has shown that the power of $18 \mathrm{~W}$ and $100 \mathrm{~W}$ LED luminaires can be controlled accurately with error at 2-5\%. A solar LED street lighting system using constant-power and dimming control was designed and built for field test in a remote area. The long-term performance was satisfactory and no any failure since the installation. Since no high-power capacitor is used in the present constant-power control circuit, a longer lifetime is expected.
\end{abstract}

(c) 2012 Elsevier Ltd. All rights reserved.

Keywords: LED driving; Stand-alone solar LED lighting; Solar LED lighting; Solar energy; LED; Solar lighting

\section{Introduction}

Application of stand-alone solar PV system in remote areas where the grid power cannot reach has been proved economically feasible. However, the reliability and continuous service time in a continuous bad weather are the two key factors influencing the acceptability of this technology.

A high-performance stand-alone solar LED lighting system was developed by Huang et al. (2010a) for LED lighting. The system adopts the near-maximum-power-point operation (nMPPO) concept for the design of photovoltaic power generation system (Huang et al., 2006) to get rid of the maximum-power-point-tracking controller (MPPT) just by properly matching the PV module specification with the battery voltage to obtain a similar performance of MPPT. The additional cost, reliability problem, and energy loss of the MPPT is thus avoided.

To charge the battery in its full storage capacity, a 3phase battery charge using pulse-width modulation

\footnotetext{
* Corresponding author. Tel.: +886 23634790; fax: +886223640549. E-mail address: bjhuang@seed.net.tw (B.-J. Huang).
}

(PWM) and feedback control technique was developed by Huang et al. (2010b).

Since the $I-V$ curve of a LED lamp is sensitive in voltage, as shown in Fig. 1. A slight variation of applied voltage may cause abrupt change of current which may damage the LED. The constant-voltage driver was thus not recommended for LED. Instead, the constant-current driving is widely used in commercial products. A DC/DC converter with constant-current output for LED is thus needed in solar LED lighting system. This creates the problems of energy loss in the control circuit of the converter, decreasing solar system reliability, and increasing cost.

A lot of commercial DC/DC constant-current driver products for LED illumination are available. However, the energy conversion loss for high-power LED is high $(>14 \%)$ at partial load condition, for example, the product of Zetex Semiconductors Plc. (2008). This happens when a dimming control of LED is employed. The cost of a DC/ DC constant-current driver for 30-200 W LED is around 30-50 USD. Moreover, the lifetime of high-power DC/ DC converter is expected to be around 3 years due to the capacitor failure in the circuit. 


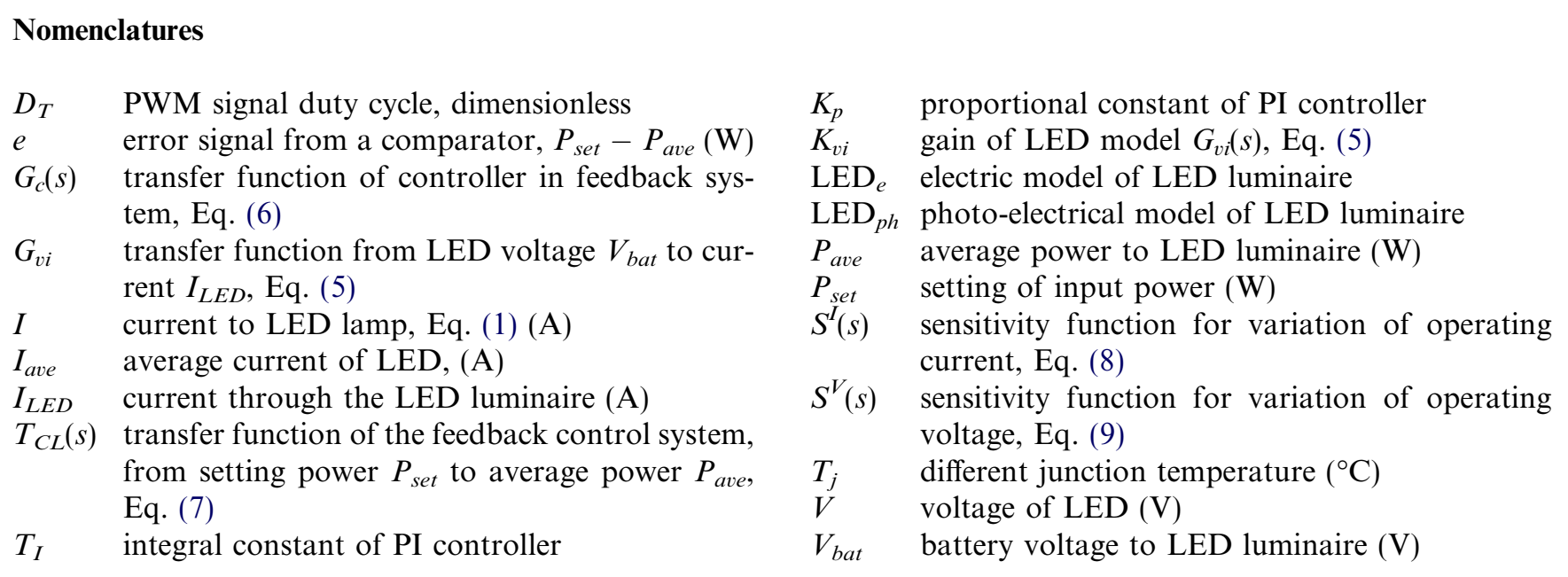

To eliminate the DC/DC converter for LED lighting, Huang et al. (2010a) developed a special technology to drive LED directly by battery voltage using a PWM technique with constant average current control. A reliability test for the illumination of LED lamps was performed continuously for $13,200 \mathrm{~h}$ and shows that the light decay of

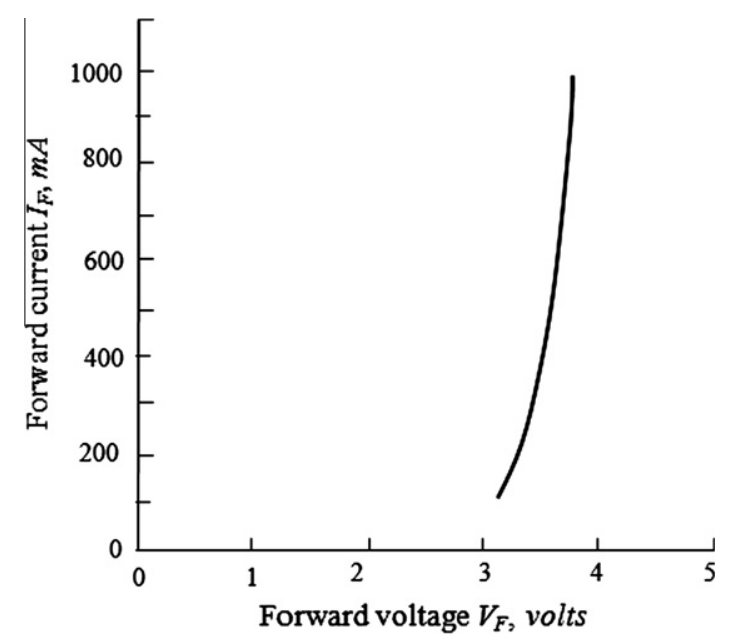

Fig. 1. $I-V$ curve of a LED at junction temperature $25^{\circ} \mathrm{C}$.
PWM-driven LED is the same as that of constant-current driven LED.

The electrical performance of LED behaves like a negative-temperature resistance. The electrical resistance of LED decreases with increasing temperature. The driving voltage as well as the input power of a constant-current driven LED may change due to variation of LED junction temperature. An illumination test of a LED luminaire carried out in the present study shows that the constant-current driven LED causes an illumination decrease about $12 \%$, and about $50 \%$ increase for constant-voltage driving, for a temperature rise of $40{ }^{\circ} \mathrm{C}$ (Fig. 2).

Huang et al. (2012) developed a constant-power LED driver using ac power input to balance the LED current supply as well as the light emission at variable operating temperatures. A linear feedback control technique was used in the design of constant-power LED driver. The test result shows that the feedback control system accurately controls the input power of LED luminaire to within 1.3 per cent error. As the ambient temperature changes from 0 to $40^{\circ} \mathrm{C}$, the LED illumination varies slightly $(-1.7 \%)$ for constant-power driving, as compared to that of constant-current driving $(-12 \%)$ and constant-voltage driving $(+50 \%)$.
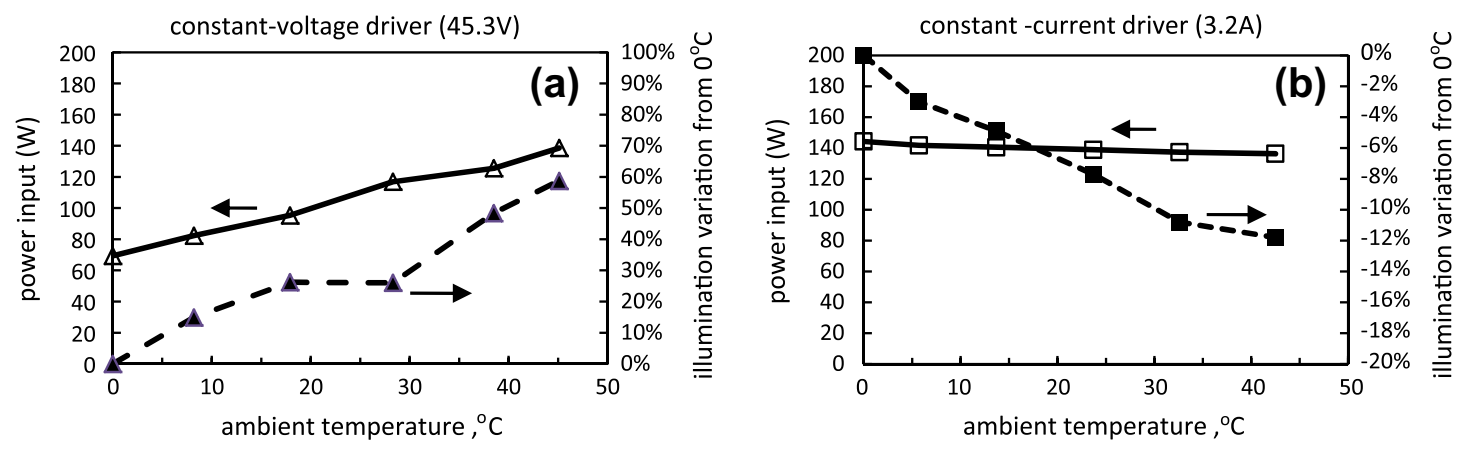

Fig. 2. Variation of LED illumination with ambient temperature for different driver. 
The constant-power driver has revealed advantage in stabilizing the illumination of LED under large temperature variation. This is important in practical application. In addition, the constant-power driver can provide an accurate power consumption control through dimming of the LED during the night in solar LED lighting.

However, for solar LED lighting, the power source comes directly from a battery whose voltage will vary during discharge. The required constant-power control is thus different from the constant-power driver using ac power source developed by Huang et al. (2012). Besides, the conventional DC/DC driver uses high-power capacitor in circuit which may cause failure in about 3 years. The constant-power driving in solar LED lighting doesn't use high-power capacitor in circuit and will have longer lifetime.

In the present study, we intend to develop a constantpower control system for LED which is directly driven by battery in solar-powered lighting system. A solar LED lighting system using the constant-power and dimming control for LED lighting at night was designed, built, and tested in a remote area to verify this technology.

\section{Constant-power feedback control for LED driven by battery}

\subsection{Feedback structure of constant-power control for LED driven by battery}

The feedback structure of the LED constant-power control system driven directly by battery is shown in Fig. 3. It is seen that no high-power capacitor is used in the circuit like conventional DC/DC driver. Hence, longer lifetime is expected for the constant-power driver.

The electric model of LED luminaire $\left(\operatorname{LED}_{e}\right), G_{v i}$, receives the battery voltage as the input and creates the current through the LED luminaire $I_{L E D}\left(=G_{v i} \times V_{b a t}\right)$. The MOSFET switching device then receives a PWM signal from the controller with specific duty cycle to create a PWM current input to the LED luminaire which will generate light output due to photo-electrical effect $\left(\operatorname{LED}_{p h}\right)$. The PWM current is measured and averaged using an average current measuring device to obtain the average current signal $I_{\text {ave }}$ which will merge with the battery voltage signal in a multiplier device to obtain the average power $P_{\text {ave }}$. The comparator will compare Pave with the set value $P_{\text {set }}$ and generate an error signal $e\left(=P_{\text {set }}-P_{\text {ave }}\right)$ to the controller $G_{c}(s)$ which will output a PWM signal to MOSFET from the calculation in the controller. The controller $G_{c}(s)$ can be designed based on a known LED luminaire dynamics model $G_{v i}$ according to the desired system response and disturbance rejection etc.

\subsection{Derivation of system dynamic model of LED luminaire for control system design}

The current response $I_{L E D}$ caused by the voltage input $V_{b a t}$ is much shorter than $1 m s$ in LED and can be approximated as an instantaneous process, as compared to the thermal response (Abdelkader et al., 1992). Hence, the voltage to current model $G_{v i}(s)$ can be treated as a quasisteady system with a constant gain $K_{v i}$.

Actually, the gain of $K_{v i}$ is the slope of the $I-V$ curve of LED luminaire, i.e. electrical conductance. $K_{v i}$ can then be derived from a steady-state measurement of current-tovoltage relation ( $I-V$ curve).

The $I-V$ curve of LED luminaire can be derived from the $I-V$ curve of a single LED lamp using network analysis. The single LED lamp is driven by a constant-voltage power supply and the current under different voltages are measured at fixed junction temperature.

Since the $I-V$ curve varies with LED junction temperature, a cooling device made from a thermoelectric cooler with a control system was developed to control the LED junction temperature during the experiment. The measurement of LED junction temperature uses the pulse method

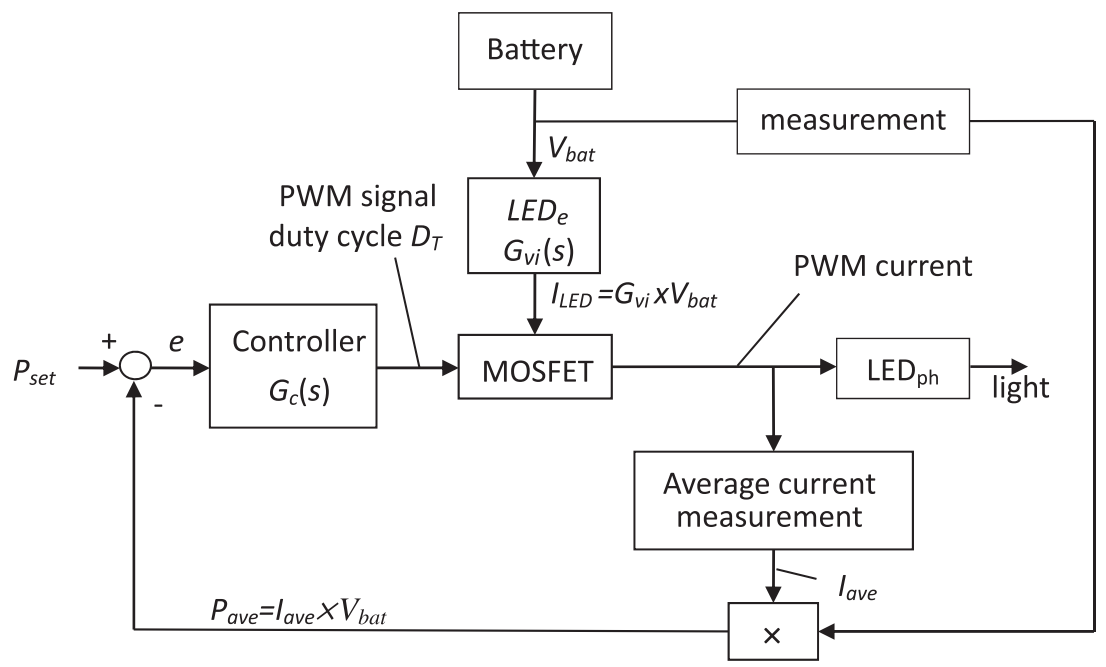

Fig. 3. Feedback structure of LED constant-power control system. 


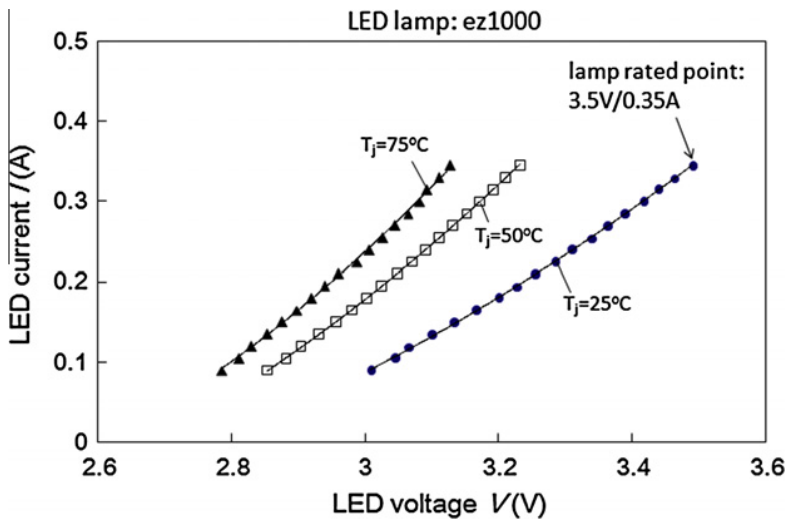

Fig. 4. $I-V$ curves of a LED lamp at different junction temperatures.

developed by Huang et al. (2009). A low current pulse $(1 \mathrm{~mA})$ with short time duration $(50 \mu \mathrm{s})$ was applied to the LED lamp when the junction temperature is in equilibrium with a test chamber holding the test section. The voltage was then measured and the junction temperature was determined using the predetermined $V-T_{j}$ relation at low current $(1 \mathrm{~mA})$. The experiment was conducted using a LED lamp ez-1000 (made by Cree) at $T_{j}=25,50,75^{\circ} \mathrm{C}$. The measurement result of $I-V$ relation of the LED lamp is shown in Fig. 4.

A quadratic function can be derived to fit the $I-V$ curve of Fig. 4:

$I=a_{o} V^{2}-a_{1} V+a_{2}$

where $a_{0}, a_{1}, a_{2}$ are the fitted parameters for different junction temperature $T_{j}$. Applying the perturbation relations,

$\tilde{V}(t)=V(t)-\bar{V}$

$\tilde{I}(t)=I(t)-\bar{I}$

to Eq. (1) and neglecting the second-order term, $\tilde{V} \tilde{V}$, we obtain the following relation:

$\tilde{I}=\left(2 a_{o} \bar{V}-a_{1}\right) \tilde{V}$

Taking the Laplace transform of Eq. (4), the dynamics model for a single LED lamp can be expressed:

$G_{v i}(s)=\frac{\tilde{I}}{\tilde{V}}=2 a_{o} \bar{V}-a_{1} \equiv K_{v i}$

Two kinds of LED luminaire, $100 \mathrm{~W}$ and $18 \mathrm{~W}$, was selected for experiment in the present study. The $100 \mathrm{~W}$ luminaire consists of 84 LED lamps with 7 in series and 12 in parallel and the $18 \mathrm{~W}$ luminaire consists of $15 \mathrm{LED}$ lamps with 3 in series and 5 in parallel. The dynamics model of the luminaire can be easily derived using electrical network principle. Table 1 shows the derived parameters $a_{o}$ $a_{1}, a_{2}$ and the model $K_{v i}$ of a single LED lamp and the $18 \mathrm{~W}$ and $100 \mathrm{~W}$ LED luminaire.

The derived linear system dynamics model of the LED luminaire will be used in the design of the feedback control system.
Table 1

Determination of the model parameters and $K_{v i}$ for a single LED lamp and the $18 \mathrm{~W} / 100 \mathrm{~W}$ luminaire.

\begin{tabular}{llllll}
\hline $\begin{array}{l}T_{j}, \\
{ }^{\circ} \mathrm{C}\end{array}$ & $a_{o}$ & $a_{1}$ & $a_{2}$ & $\begin{array}{l}K_{v i}(\text { single } \\
\text { LED })\end{array}$ & $\begin{array}{l}K_{v i}(18 \mathrm{~W} / 100 \mathrm{~W} \\
\text { luminair })\end{array}$ \\
\hline 25 & 0.2037 & 0.7955 & 0.6408 & 0.5298 & $0.8830 / 0.9082$ \\
50 & 0.3140 & 1.2322 & 1.0487 & 0.6746 & $1.1243 / 1.1565$ \\
75 & 0.4193 & 1.7481 & 1.7069 & 0.7456 & $1.2427 / 1.2782$ \\
\hline
\end{tabular}

\subsection{Controller design}

The PI (Proportional-Integral) algorithm was chosen as the controller of the LED constant-power feedback control system (Fig. 3):

$G_{c}(s)=K_{p}\left(1+\frac{1}{T_{I} S}\right)$

From the feedback structure of Fig. 3 with PI controller, Eq. (6), the closed-loop system transfer function can be derived as:

$T_{C L}(s)=\frac{P_{\text {ave }}(s)}{P_{\text {set }}(s)}=\frac{K_{p} T_{I} I_{\text {ave }} V_{\text {bat }} s+K_{p} I_{\text {ave }} V_{\text {bat }}}{T_{I}\left(1+K_{p} I_{\text {ave }} V_{\text {bat }}\right) s+K_{p} I_{\text {ave }} V_{\text {bat }}}$

where $I_{a v e}=D_{T} K_{v i} V_{b a t}, D_{T}$ is the duty cycle of MOSFET, $K_{v i}=G_{v i}$ according to Eq. (5).

The design criterion for the present constant-power feedback control system of solar LED lighting is set as, according to the step response:

(1) Rise time (the time of step response from $10 \%$ to $90 \%$ of the final steady value) $<0.5 \mathrm{~s}$

(2) Settling time (the time of step response to reach $98 \%$ steady value) $<1 \mathrm{~s}$.

The two parameters of the PI controller, $K_{p}$ and $T_{I}$, can be determined from the control system simulation using Matlab/Simulink, as shown in Fig. 5 which includes the anti-windup loop for the saturation phenomenon in integral control.

The IAE (integral of absolute error) is used as the design criteria to determine the suitable controller parameters. A smaller IAE value represents smaller control error.

$\mathrm{IAE}=\int\left|P_{\text {set }}-P_{\text {ave }}(t)\right| d t$

The proportional constant $K_{p}$ of the PI controller was first tuned without the integral control. It was found that the system response maintains about the same at $K_{p}>0.3$. But a higher value of $K_{p}$ also easily causes saturation of the actuator. Therefore $K_{p}$ is chosen as 0.3. The integral constant $T_{I}$ is then tuned at $K_{p}=0.3$. The results are shown in Table 2. It is seen that the rise time varies slowly at $T_{I}<1 / 12$. IAE decreases with decreasing $T_{I}$. The step response for various $T_{I}$ shown in Fig. 6 also reveals that $T_{I}=1 / 12$ is good enough to meet the design criterion. 


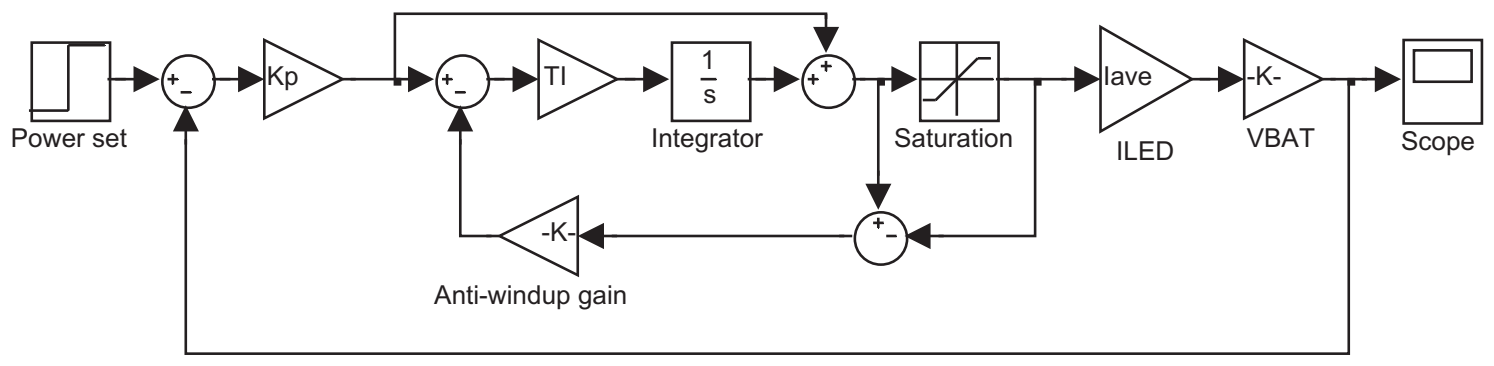

Fig. 5. Simulation block diagram with an anti-windup loop.

Table 2

Variation of step response parameters with $T_{I}$ at $K_{p}=0.3$.

\begin{tabular}{lllllll}
\hline$T_{I}$ & Set 1 & Set 2 & Set 3 & Set 4 & Set 5 & Set 6 \\
\cline { 2 - 7 } & $1 / 6$ & $1 / 9$ & $1 / 12$ & $1 / 15$ & $1 / 18$ & $1 / 21$ \\
\hline Rise time $(s)$ & 0.37 & 0.25 & 0.18 & 0.15 & 0.12 & 0.11 \\
Settling time $(s)$ & 0.66 & 0.44 & 0.33 & 0.27 & 0.22 & 0.19 \\
IAE value & 0.361 & 0.290 & 0.255 & 0.235 & 0.225 & 0.217 \\
\hline
\end{tabular}

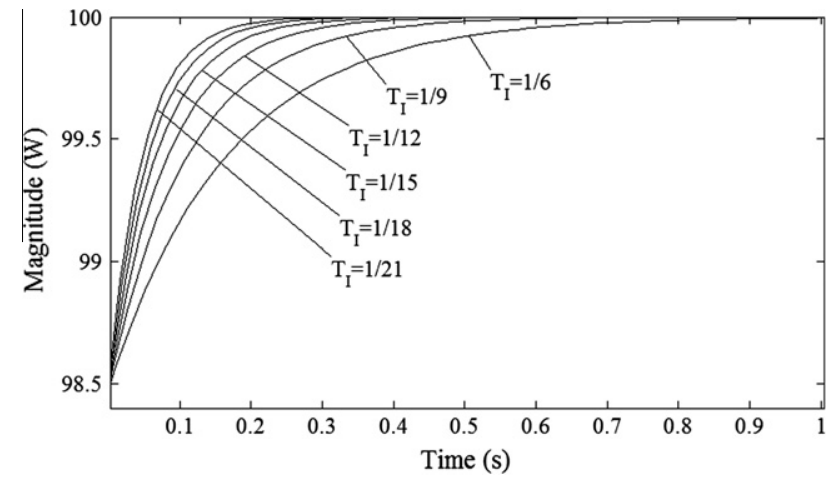

Fig. 6. Simulation result of step response for $K_{p}=0.3, T_{I}=1 / 6-1 / 21$.

The parameter tuning of PI controller described above is according to the step response of the given control command (constant power setting). It may not be robust with respect to the plant uncertainty and disturbance (Zhou et al., 1996). For future application in solar LED lighting, the battery voltage as well as the LED driving current may vary with environment. The controller then should be able to reject the disturbances from environment. Here, we use a sensitivity function which is defined as the variation of closed-loop transfer function $T_{C L}(s)$, Eq. (7), with respect to the operating variables in $T_{C L}(s)$, that are $I_{\text {ave }}$ and $V_{\text {bat }}$ (Franklin et al., 1994). Therefore, the sensitivity functions $S^{I}(s)$ and $S^{V}(s)$ are defined and derived as:

$$
\begin{aligned}
& S^{I}(s)=\frac{I_{\text {ave }}}{T_{C L}} \frac{\partial T_{C L}(s)}{\partial I_{\text {ave }}}=\frac{T_{I} s}{T_{I}\left(1+K_{p} I_{\text {ave }} V_{\text {bat }}\right) s+K_{p} I_{\text {ave }} V_{\text {bat }}} \\
& S^{V}(s)=\frac{V_{\text {bat }}}{T_{C L}} \frac{\partial T_{C L}(s)}{\partial V_{\text {bat }}}=\frac{T_{I} S}{T_{I}\left(1+K_{p} I_{\text {ave }} V_{\text {bat }}\right) s+K_{p} I_{\text {ave }} V_{\text {bat }}}
\end{aligned}
$$

It is seen that $S^{I}(s)=S^{V}(s) . S^{I}(s)$ or $S^{V}(s)$ represents the ratio of the closed-loop transfer function change rate with respect to the change rate of $I_{\text {ave }}$ or $V_{\text {bat }}$. Lower sensitivity implies that the closed-loop gain is less sensitive to the variation of operating variable $I_{\text {ave }}$ or $V_{\text {bat }}$. Substituting the design parameters of the PI controller, $K_{p}, T_{I}$, into the sensitivity functions, Eqs. (8) and (9), and calculate their frequency response. By examine the gain of the sensitivity function, we can check the robustness of the controller design.

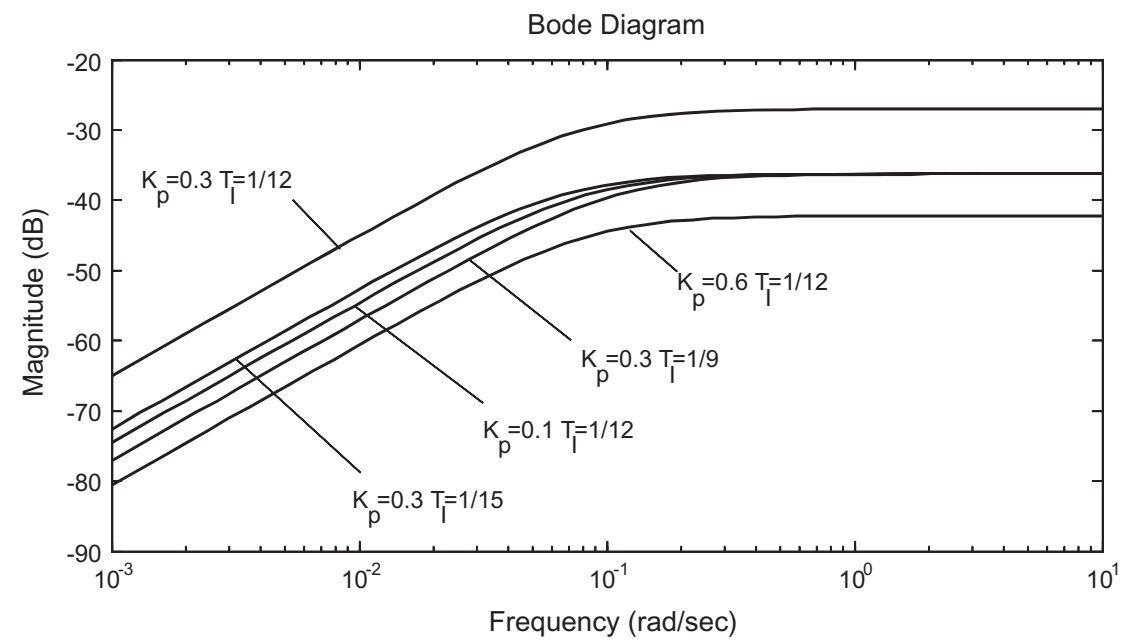

Fig. 7. Frequency response of closed-loop sensitivity function $S^{I}(s)=S^{V}(s)$ at $I_{\text {ave }}=8.4 \mathrm{~A}, V_{\text {bat }}=25.4 \mathrm{~V}$. 


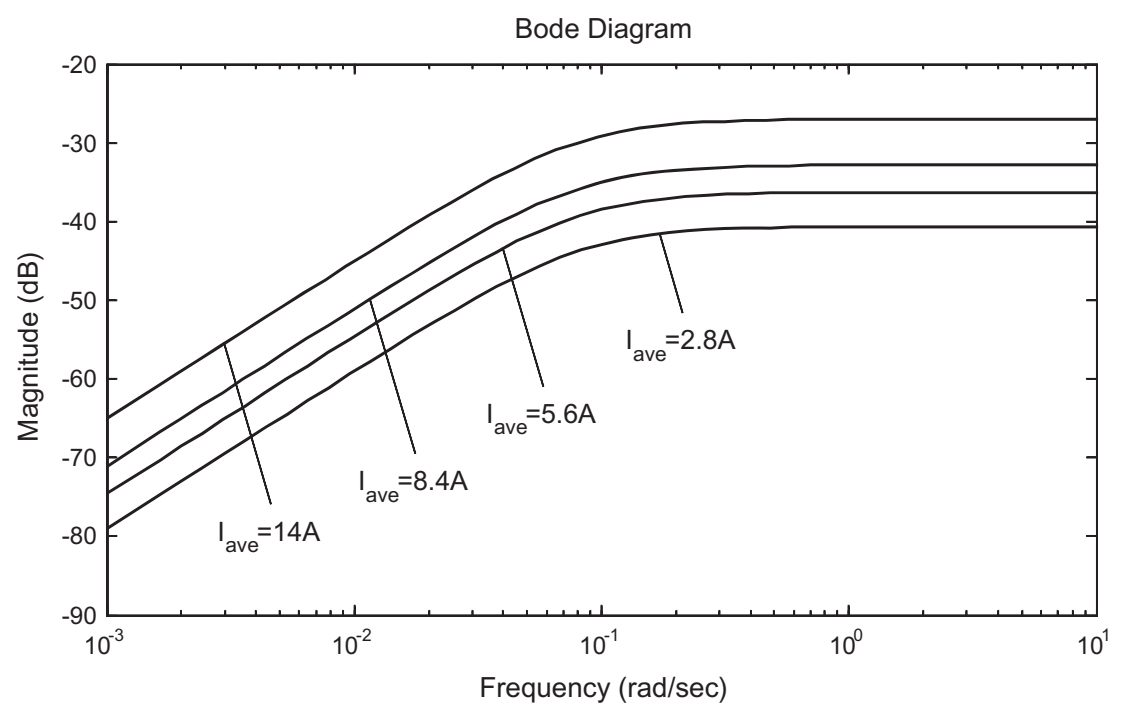

Fig. 8. Frequency response of closed-loop sensitivity function $S^{I}(s)=S^{V}(s)$ at $K_{p}=0.3, T_{I}=1 / 12, V_{b a t}=25.4 \mathrm{~V}$.
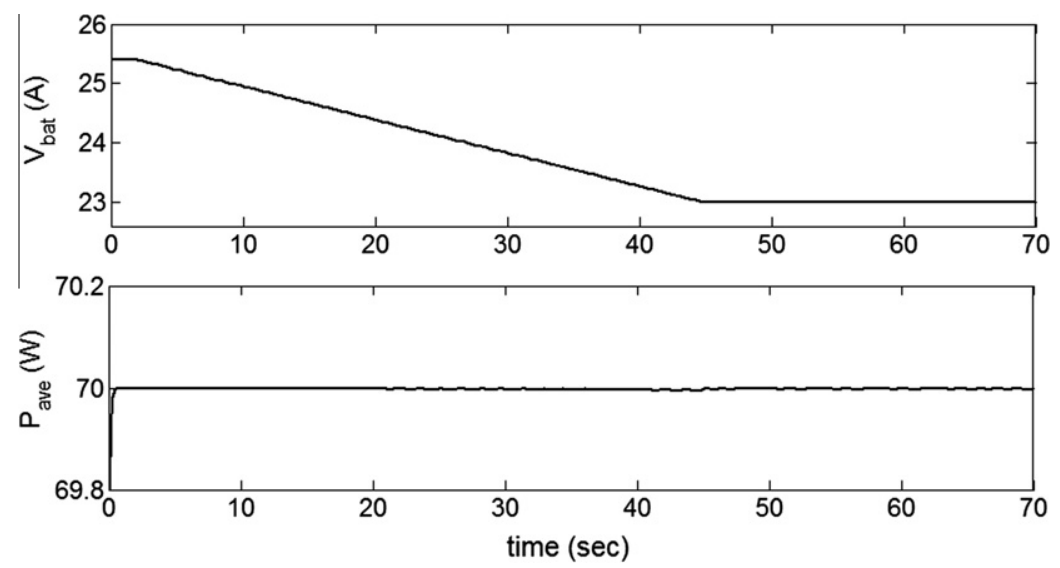

Fig. 9. Control system simulation result of $100 \mathrm{~W}$ LED luminaire at $P_{\text {set }}=70 \mathrm{~W}$ under disturbance of $V_{\text {bat }}$.

It is seen from Fig. 7, that the gain of the sensitivity function, $S^{I}(j \omega)=S^{V}(j \omega)$, is less than $-30 \mathrm{db}$ at different parameters of the PI controller. $K_{p}=0.3$ and $T_{I}=1 / 12$ seems suitable for the PI controller. Fig. 8 is the gain of sensitivity function at various $I_{\text {ave }}$ for $V_{b a t}=25.4 \mathrm{~V}$ and $K_{p}=0.3$ and $T_{I}=1 / 12$. The sensitivity is seen always less than $-30 \mathrm{~dB}$ over a wide range of frequency and current $I_{\text {ave }}$ (from $2.8 \mathrm{~A}$ to $14 \mathrm{~A}$ ).

From the above discussion, the transfer function of the controller is chosen as

$G_{c}(s)=0.3\left(1+\frac{1}{12 s}\right)$

\subsection{Control system simulation}

To verify the above controller design, we carried out a time-domain simulation using Simulink to check the control accuracy under a disturbance of battery voltage.
Fig. 9 shows the simulation result of the $100 \mathrm{~W}$ LED with power setting at $70 \mathrm{~W}$. It is seen that the LED power
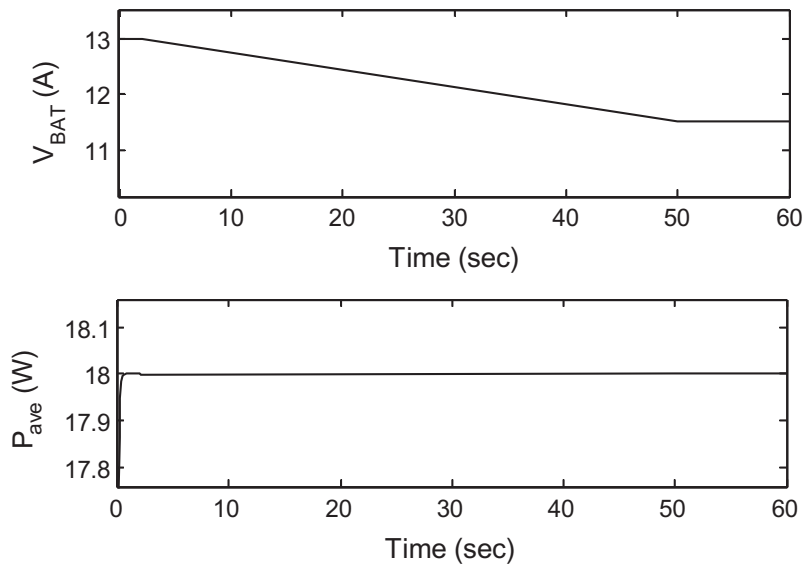

Fig. 10. Control system simulation result of $18 \mathrm{~W}$ LED luminaire at $P_{\text {set }}=18 \mathrm{~W}$ under disturbance of $V_{\text {bat }}$. 


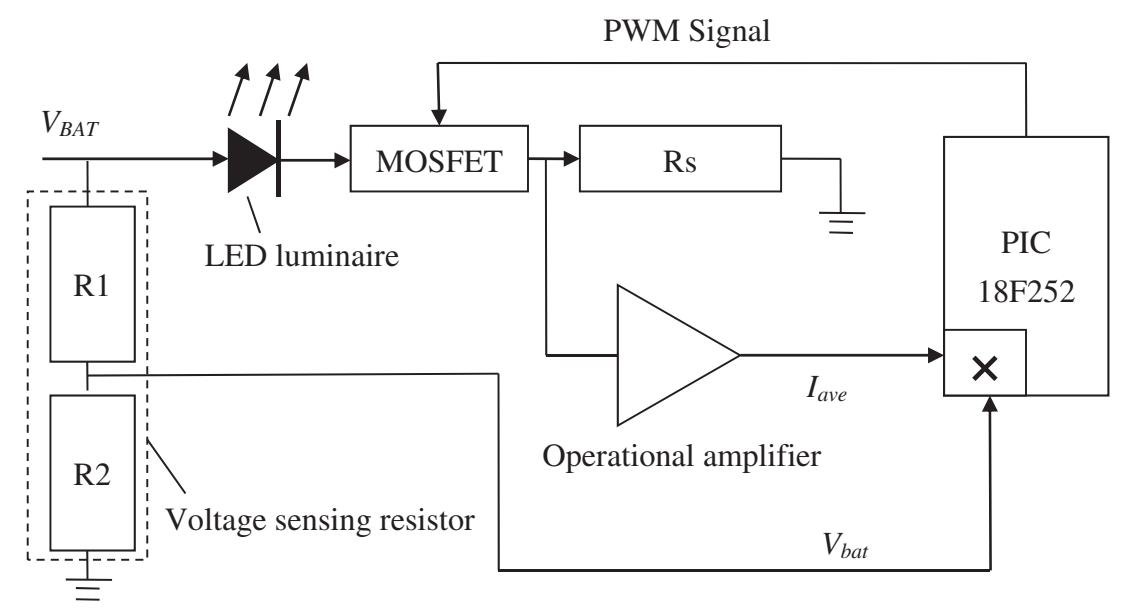

Fig. 11. Implementation of LED constant-power control system.

$P_{\text {ave }}$ remains steady at $70 \mathrm{~W}$ without any disturbance caused by a fast battery voltage change from $25.4 \mathrm{~V}$ to $23 \mathrm{~V}$ in $40 \mathrm{~s}$.

The simulation of the $18 \mathrm{~W}$ LED luminaire using the same controller with battery voltage changes from $13.0 \mathrm{~V}$ to $11.5 \mathrm{~V}$ in $50 \mathrm{~s}$ was carried out and the result is shown in Fig. 10. The LED power $P_{\text {ave }}$ remains steady and at the setting value $18 \mathrm{~W}$ without any disturbance.

\subsection{Control system implementation and test}

The present design of LED constant-power control system was implemented in a PIC microprocessor-based control system built in the laboratory (Fig. 11). No high-power capacitor is used in the circuit and longer lifetime is expected.

The instantaneous current through the LED luminaire was detected by the voltage across a standard resistor Rs which is small enough $(0.003 \mathrm{ohm})$ to reduce energy loss. An OP (LM324) is used to amplify the voltage across the resistance $R s$ and the signal is sent to the microprocessor in which it is integrated and averaged to obtain $I_{\text {ave }}$.

The battery voltage $V_{\text {bat }}$ was measured by the voltage across the sensing resistor $\mathrm{R} 2$ for the microprocessor to read. The resistor R1 is used to create a voltage drop from battery such that the voltage across R2 is low enough to be measured by the microprocessor. The average power was calculated from the multiplication of average current $I_{\text {ave }}$ and battery voltage $V_{\text {bat }}$. The controller software stored in the PIC then calculates the control signal (PWM signal, duty cycle $D_{T}$ ) using the PI algorithm described previously and actuates the MOSFET to output a PWM current to drive the LED luminaire.

We used a power supply with adjustable voltage to drive LED to test the control accuracy under battery voltage disturbance. Fig. 12 shows the test results for the $100 \mathrm{~W}$ LED luminaire whose power was set at $70 \mathrm{~W}$. The voltage was changed from $25.9 \mathrm{~V}$ to $23 \mathrm{~V}$ (about $12 \%$ ) during the test. The measured average LED power input Pave is $69.9 \mathrm{~W}$,

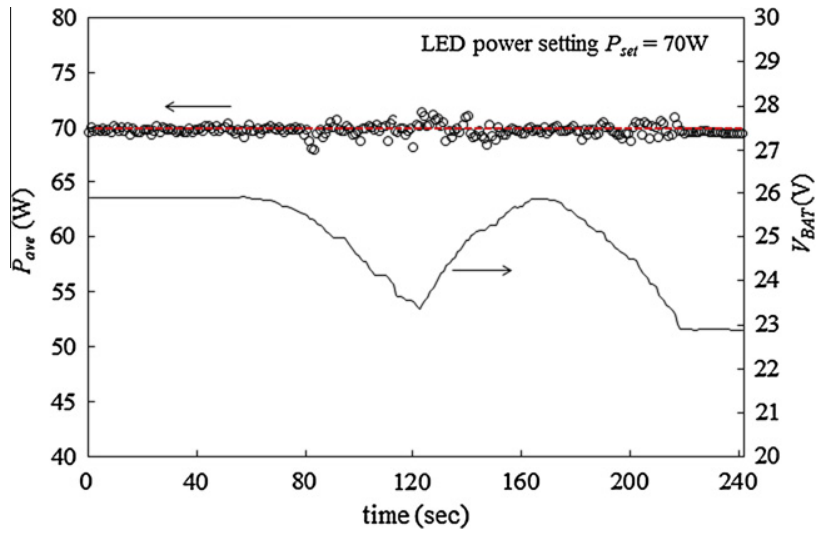

Fig. 12. Constant-power control system test result of $100 \mathrm{~W}$ LED luminaire

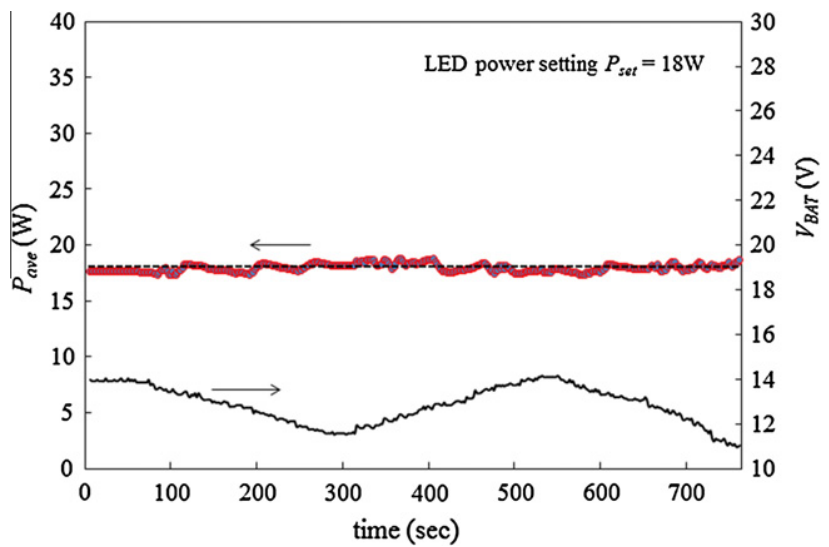

Fig. 13. Constant-power control system test result of $18 \mathrm{~W}$ LED luminaire.

with standard deviation $0.38 \mathrm{~W}$. The maximum deviation is $1.39 \mathrm{~W}, 2 \%$ of the setting value $70 \mathrm{~W}$. Fig. 13 shows the result of the $18 \mathrm{~W}$ LED luminaire under the similar control system test with voltage change from $14.2 \mathrm{~V}$ to $11 \mathrm{~V}$ (about $22.5 \%$ ). The measured average LED power input Pave is $17.95 \mathrm{~W}$, with standard deviation $0.35 \mathrm{~W}$. 
The maximum deviation is $0.88 \mathrm{~W}, 4.9 \%$ of the setting value $18 \mathrm{~W}$. The test results verify that the feedback control system using PI controller can obtain a robust property with respect to a large disturbance of voltage.

\section{Field test of constant-power driving in solar street lighting}

\subsection{Design and installation of solar LED street lighting system}

The constant-power control technology for LED lighting directly driven by battery was developed in the present study. The control accuracy of the LED input power under variable battery voltage disturbance was verified experimentally. A solar LED street lighting system was then designed and built for long-term field test in a remote area (Ali Tribe), which is located in the high mountain area of southern Taiwan. Fig. 14 shows the photo of the installation.

The design of the solar LED street lighting system follows the high-performance stand-alone solar LED lighting technology developed by Huang et al. (2010a) which has three unique features: (1) using the near-maximumpower-point operation (nMPPO) concept in the design of photovoltaic power generation system (Huang et al., 2006) to avoid the maximum-power-point-tracking controller (MPPT); (2) to continue charging the battery after the overcharge point using PWM control technique for more and safe charged energy; (3) to drive LED for lighting directly from the battery using constant-current control technique, which was replaced with the present constantpower control technology.

The constant-power LED driver has revealed advantage in stabilizing the illumination of LED under large

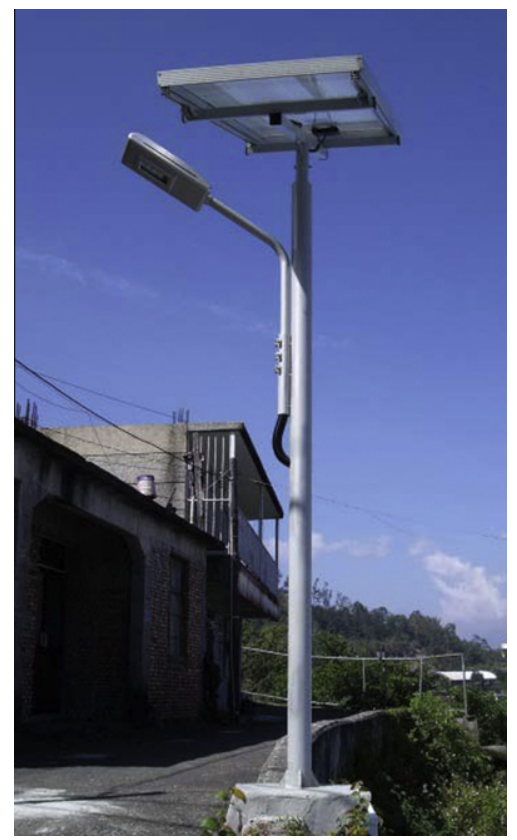

Fig. 14. Ali's $18 \mathrm{~W}$ solar LED street lighting system. temperature variation (Huang et al., 2012). The constantpower driver can also provide an accurate energy consumption control through dimming of the LED power during the night. We adopted the constant-power control for solar LED lighting as described above and also added a dimming control of LED to save energy.

Based on the nMPPO concept (Huang et al., 2006), the solar LED lighting system consists of a $18 \mathrm{~W}$ LED (12 V), a $130 \mathrm{Wp}$ solar PV module, and a $100 \mathrm{~A} \mathrm{~h} / 12 \mathrm{~V}$ lead-acid battery. The net illumination of the $18 \mathrm{~W}$ LED luminaire is 1300 lumen at $18 \mathrm{~W}$ input. A microprocessor(PIC)-based solar charging/discharging controller was designed and built according to the constant-power control technique described above, for battery charging control according to the 3-phase charge control technique (Huang et al., 2010b), and for LED dimming control according to a desired schedule from the constant-power setting values $\left(P_{\text {set }}\right)$ in the controller.

The LED lighting starts at half an hour after sunset and shut down at sunrise according to the measured voltage signal of the solar PV module. The dimming schedule of LED was designed with four stages: (1) full load (18 W) for $3 \mathrm{~h}$ after starting; (2) linearly decreasing from $18 \mathrm{~W}$ to $9 \mathrm{~W}$ in the following $3 \mathrm{~h}$; (3) linearly decreasing from $9 \mathrm{~W}$ to $4.5 \mathrm{~W}$ in the next $3 \mathrm{~h}$; (4) setting constant $4.5 \mathrm{~W}$ until the LED turned off at dawn. The time step used in the dimming schedule is $6 \mathrm{~min}$. The setting of the dimming schedule is quite easy since the input power of LED in Watt is used. The dimming schedule can also be changed anytime by editing the software of the microprocessor-based control system.

\subsection{Field test of solar LED street lighting system}

This solar street lighting system was installed and started to run in June, 2011. The control system was also designed with data acquisition function to record the long-term performance. Fig. 15 shows the field test result of LED dimming control at night. It is seen that the constant-power control performs satisfactory in tracking the dimming schedule. The control error of $P_{\text {ave }}$ away from

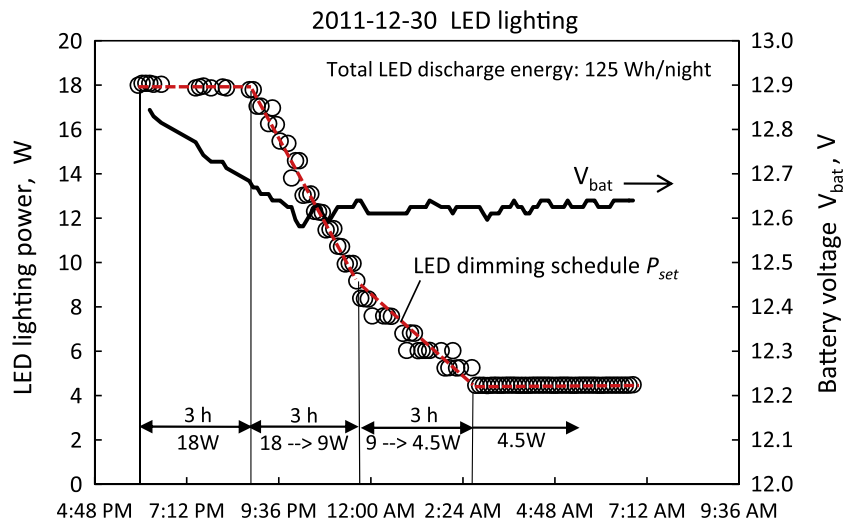

Fig. 15. Field test result of control at LED dimming night. 


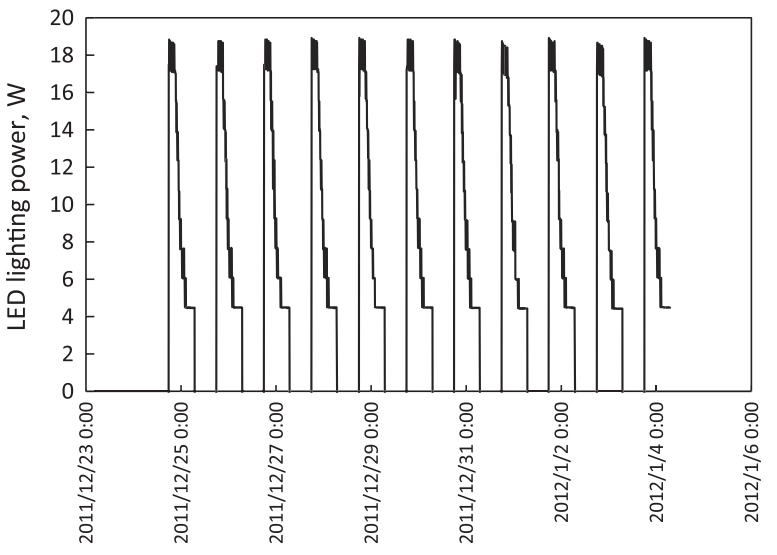

Fig. 16. Long-term record of LED dimming performance.

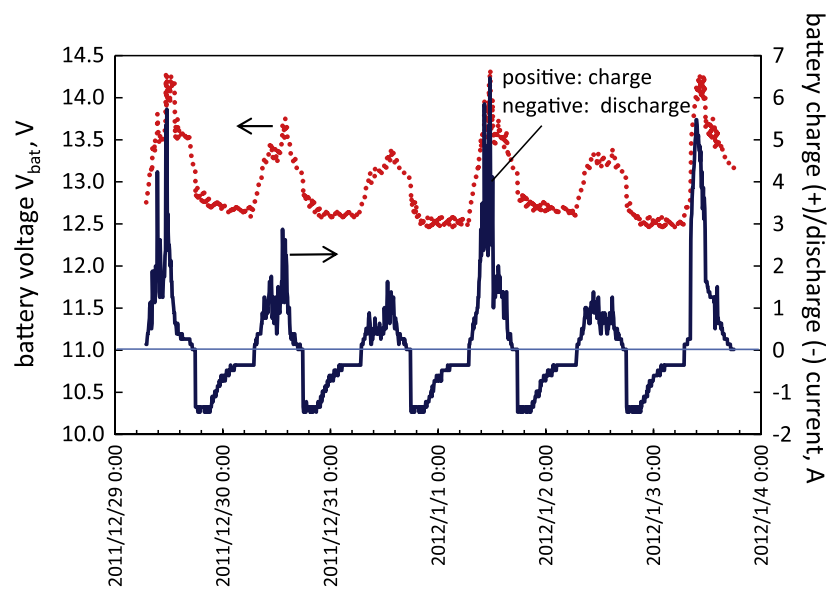

Fig. 17. Long-term performance in battery charging and discharging (LED lighting).

the dimming schedule $P_{\text {set }}$ is mainly due to the larger time step $(6 \mathrm{~min})$ used in the dimming time schedule. Another source of error may come from the measurement error of $P_{\text {ave }}$ inside the control system. The total energy consumption of LED lighting was $125 \mathrm{Wh}$ per night.

The solar street lighting system has been run for more than 14 months without any failure. Fig. 16 is the continuous record for 11 nights which shows good performance in LED dimming control.

Fig. 17 shows the long-term performance for battery charging at daytime and discharging (LED lighting) at night. The battery voltage higher than $14 \mathrm{~V}$ implies that the weather is clear with high solar irradiation so that the battery is charged over the overcharge point $(14.1 \mathrm{~V})$ and the PWM charging control (Phase 2) was activated (Huang et al., 2010b). The field test data shows that one clear-day charging can provide LED lighting for at least three consequent nights as can be seen from December 29, 2011.

\section{Conclusion}

A direct battery-driven LED lighting technology using constant-power control is proposed for LED luminaire in the present study. A system dynamics model of LED luminaire was derived and used in the design of the feedback control system. The PI algorithm was adopted in the controller. The test result of the control system has shown that the power of $18 \mathrm{~W}$ and $100 \mathrm{~W}$ LED luminaires can be controlled accurately with error $2-5 \%$ at battery voltage change $12-22.5 \%$.

A real solar LED street lighting system using the constant-power control technique was then designed and built for long-term field test in a remote area.

The design of the solar LED street lighting system has three unique features: (1) using the near-maximumpower-point operation (nMPPO) concept in the design of photovoltaic power generation system (Huang et al., 2006) to avoid the maximum-power-point- tracking controller (MPPT); (2) to charge the battery after the overcharge point using PWM control technique; (3) to drive LED for lighting directly from the battery using constant-power control technique developed in the present study.

A microprocessor(PIC)-based solar charging/discharging controller was designed and built for LED lighting control according to the constant-power control technique, for battery charging control according to the 3-phase charge control technique (Huang et al., 2010b), and for LED dimming control according to a desirable schedule using the time-variant constant-power setting values $\left(P_{\text {set }}\right)$ in the controller.

The dimming schedule of LED was designed with four modes from $18 \mathrm{~W}$ in full load at beginning to $4.5 \mathrm{~W}$ before sunrise. It was shown that the constant-power control performs satisfactory in tracking the dimming schedule. The total energy consumption of LED lighting was $125 \mathrm{Wh}$ per night.

The field test data shows that one clear-day charging can provide LED lighting for at least three consequent nights. The long-term performance for battery charging at daytime and discharging (LED lighting) at night was found satisfactory and no any failure since the installation. This verifies the technical feasibility of constant-power control for LED lighting and its application in solar lighting system.

\section{Acknowledgement}

This publication is based on work supported by Award No. KUK-C1-014-12, made by King Abdullah University of Science and Technology (KAUST), Saudi Arabia.

\section{References}

Abdelkader, H.I., Hausien, H.H., Martin, J.D., 1992. Temperature rise and thermal rise time measurement of a semiconductor laser diode. Review of Scientific Instruments 63 (3), 2004-2007.

Franklin, G.F., Powell, J.D., Emami-Naeini, A., 1994. Feedback Control of Dynamic Systems, third ed. Addison-Wesley (Chapter 4).

Huang, B.J., Sun, F.S., Ho, R.W., 2006. Near-maximum-power-pointoperation (nMPPO) design of photovoltaic power generation system. Solar Energy 80, 1003-1020. 
Huang, Bin-Juine, Tang, Chun-Wen, Wu, Min-Sheng, 2009. System dynamics model of high-power LED luminaire. Applied Thermal Engineering 29, 609-616.

Huang, B.J., Wu, M.S., Hsu, P.C., Chen, J.W., Chen, K.Y., 2010a. Development of high-performance solar LED lighting system. Energy Conversion and Management 51, 1669-1675.

Huang, B.J., Hsu, P.C., Wu, M.S., Ho, P.Y., 2010b. System dynamic model and charging control of lead-acid battery for stand-alone solar PV system. Solar Energy 84, 822-830.
Huang, Bin-Juine, Chen, Chun-Wei, Ong, Chin-Dian, Du, Bo-Han, Hsu, Po-Chien, 2012. Development of constant-power driving control for LED luminaire. Applied Thermal Engineering, accepted for publication.

Zetex Semiconductors Plc., 2008. ZXLD1320 Buck Mode DC-DC Converter for LED Driving with 1.5 A Output and Current Control. Issue 1 - January $2008<$ http://www.zetex.com>.

Zhou, K., Doyle, J.C., Glover, K., 1996. Robust and Optimal Control. Prentice-Hall, Upper Saddle River, NJ. 